\title{
Grooved Pegboard Test
}

National Cancer Institute

\section{Source}

National Cancer Institute. Grooved Pegboard Test. NCI Thesaurus. Code C85394.

A manipulative dexterity test using a pegboard device with five rows of five holes. It

features 25 key-style pegs with holes in various positions in space, and is especially good for testing lateralized brain damage. 